\title{
Early Development of Two Types of Nicotinic Acetylcholine Receptors
}

\author{
R. J. Leonard, S. Nakajima, ${ }^{\mathrm{a}}$ Y. Nakajima, ${ }^{\mathrm{b}}$ and C. G. Carlson ${ }^{\mathrm{c}}$ \\ Department of Biological Sciences, Purdue University, West Lafayette, Indiana 47907
}

Functional changes of acetylcholine receptor (AChR) channels in embryonic Xenopus myotomal muscle cells were examined during their development in culture. Single-channel currents evoked by $\mathbf{5 0}$ or $\mathbf{5 0 0} \mathrm{nm}$ ACh were measured using the patch-clamp technique. In Xenopus myocytes the first emergence of AChRs takes place at about stage 20 (Nieuwkoop and Faber). Myotomes were dissociated at very early stages and plated in culture. Single-channel currents through AChRs were recorded at times ranging from a few hours (stage 21) to several days (stage 47) after the first emergence of AChRs. Two classes of AChR channel were recorded: One class had a low conductance with a long burst duration (low-conductance channel), and the other had a high conductance with a short burst duration (high-conductance channel). Both of these classes were active from the earliest time recorded (stages 21-24). One effect of development was a shift in the relative activity of the low- and high-conductance channels. Initially (stages 21-24), the low conductance channels predominated, accounting for over $95 \%$ of the observed events. After $3 \mathrm{~d}$ in culture, however, high- and low-conductance events occurred with roughly equal frequency. The other effect of development was a 4-fold decrease in the mean burst length of the low-conductance channel. The decrease in burst length took place rapidly, with about $60 \%$ of the change occuring within $24 \mathrm{hr}$ in culture. The burst length of the high-conductance channel remained virtually constant during development, as did the unitary conductance of both channels and the voltage dependence of their mean burst lengths. The deveiopmental change in the proportion of low- and high-conductance channels is likely due to the increased insertion of new highconductance channels. However, the molecular mechanism of the shortening of burst length of the low-conductance channel is unknown.

\footnotetext{
Received Sept. 22, 1987; revised Mar. 14, 1988; accepted Mar. 18, 1988

We thank Dr. Tomoyuki Takahashi for his participation during the early phase of this work. Thanks are also due to Ms. Pamella Schroeder for her technical help and to Mrs. Jan Ermel for her clerical help. This work was supported by NIH Grants NS08601, NS24711, T32-GM-07211, and a grant from the Muscular Dystrophy Association.

Correspondence should be addressed to Dr. Reid J. Leonard, Division of Biology 156-29, California Institute of Technology, Pasadena, CA 91125.

a Present address: Department of Pharmacology, University of Illinois College of Medicine at Chicago, Chicago, IL 60612.

'Present address: Department of Anatomy and Cell Biology, University of Illinois College of Medicine at Chicago, Chicago, IL 60612.

c Present address: Department of Biology, Purdue University Calumet, Hammond, IN 46323.

Copyright (C) 1988 Society for Neuroscience $0270-6474 / 88 / 114038-11 \$ 02.00 / 0$
}

Acetylcholine receptor (AChR) molecules in skeletal muscle cells are generally found to exist in 2 forms, differing in both unitary conductance and channel open time: junctional or mature receptors have a higher conductance and a shorter open time than extrajunctional or embryonic type channels (Katz and Miledi, 1972; Neher and Sakmann, 1976; Fischbach and Schuetze, 1980; Michler and Sakmann, 1980; Brehm et al., 1984; Leonard et al., 1984; Siegelbaum et al., 1984; Greenberg et al., 1985; Vicini and Schuetze, 1985). The recent discovery (Mishina et al., 1986) of a separate gene transcript encoding an adult form of the $\gamma$-subunit of bovine $\Lambda \mathrm{ChR}$ leaves little doubt that the 2 classes of $\mathrm{AChR}$ represent separate molecules, rather than different functional states of a single receptor type. Although the precise physiological significance for the existence of 2 types of AChRs is unknown, it is well-documented that the distribution and functional states of these 2 types of channels are not fixed but are labile and are altered during certain processes such as embryonic development (Fischbach and Schuetze, 1980; Michler and Sakmann, 1980; Brehm et al., 1984; Leonard et al., 1984; Siegelbaum et al., 1984) metamorphosis (Kullberg and Owens, 1986), innervation (Brenner and Sakmann, 1983), denervation (Allen and Albuquerque, 1986), or desensitization (Auerbach and Lingle, 1986; Igusa and Kidokoro, 1987).

The aim of the present paper is to describe the functional changes of AChRs during early stages of embryogenesis. Cultured Xenopus myocytes are a good system for the study of both receptor types without complication from neurotrophic effects. Even in the absence of neuronal contact, 2 classes of AChR can be observed in single-channel recordings (Clark and Adams, 1981; Brehm et al., 1984; Leonard et al., 1984; Greenberg et al., 1985). Furthermore, Xenopus myocytes can be cultured at a developmental stage prior to the first emergence of AChRs in the membrane (Bridgman et al., 1984: Leonard et al., 1984).

We previously reported a difference in the kinetics of the lowconductance AChR channel in Xenopus myocytes at 2 developmental stages (Leonard et al., 1984). In the present paper we examine the detailed time course of the shift in kinetics of the low-conductance AChR and changes in the activity of the 2 types of AChRs. We also report the temperature dependence of the conductance and burst duration of both classes of AChR.

We find that the mean burst length of the low-conductance channel is unusually long at the stage when AChRs first appear at the cell surface and that a substantial reduction of the burst length occurs during the following $24 \mathrm{hr}$ in culture. This rapid change in the gating kinetics occurs only in the small-conductance channel. The channel conductance, reversal potential, voltage dependence of burst length, and temperature dependence of both AChR types are stationary during the same period of development. 


\section{Materials and Methods}

Cell culture. Cell cultures of Xenopus myocytes were obtained at early embryonic stages before the appearance of AChRs in the surface membrane. The procedures were essentially the same as described by Bridgman et al. (1984). Male and female Xenopus were injected with $\sim 500$ units of human chorionic gonadotropin (Sigma), and about $10 \mathrm{hr}$ later eggs were collected and fertilized in vitro. The fertilized eggs were allowed to develop in 10\% Holtfreiter solution (full-strength Holtfreiter solution: $60 \mathrm{~mm} \mathrm{NaCl}, 0.6 \mathrm{~mm} \mathrm{KCl}, 0.9 \mathrm{~mm} \mathrm{CaCl}_{2}, 0.2 \mathrm{~mm} \mathrm{NaHCO}_{3}$, pH 7.2). When the embryos reached stages 13-14 (Nieuwkoop and Faber, 1967), the gel coats were stripped off, and the embryos were transferred to Steinberg's solution [ $60 \mathrm{~mm} \mathrm{NaCl}, 0.67 \mathrm{~mm} \mathrm{KCl}, 0.34 \mathrm{~mm} \mathrm{Ca}\left(\mathrm{NO}_{3}\right)_{2}$, $0.83 \mathrm{mM} \mathrm{MgSO}_{4}, 10 \mathrm{~mm}$ HEPES-NaOH buffer, pH 7.2]. The embryos were bisected to expose the notochord and myotomes. Following gentle treatment with collagenase $(1 \mathrm{mg} / \mathrm{ml}, \sim 30 \mathrm{~min})$, the myotomes were dissected away from the notochord and were dissociated in $\mathrm{Ca}^{2+}$-free, $\mathrm{Mg}^{2+}$-free Steinberg's solution containing 0.4 mM EGTA. By this time, the embryos would have reached stages 15-16. The dissociated cells were plated in culture dishes containing $60 \% \mathrm{~L}-15$ (Leibovitz) medium (GIBCO), $1 \%$ fetal calf serum, and 100 units penicillin with $100 \mu \mathrm{g} / \mathrm{ml}$ streptomycin (GIBCO). The culture dishes were kept inside a temperature-controlled chamber (Ambi-Hi-Lo Chamber, Lab-Line). At early developmental stages the temperature of the chamber was kept slightly lower $\left(18-20^{\circ} \mathrm{C}\right)$ than room temperature to retard the development and give us time to record from several myocytes at a given stage. Usually at stage 24 and thereafter, the temperature of the incubator was maintained at about $23^{\circ} \mathrm{C}$. Intact "sister" embryos were always present alongside the culture dishes. The developmental "stage" of a cultured cell was determined by observing the stage of these sister embryos. The "stage" of the myocytes in a given dish was recorded at the time the dish was transferred from the temperature-controlled chamber to the physiological set-up. Since most physiological experiments were performed at $13^{\circ} \mathrm{C}$, we assumed that the development of the cells in the experimental bath was negligible.

Single-channel recording. The cell-attached version of giga-seal patch clamp was used to record single-channel currents (Hamill et al., 1981). Experiments were performed on the stage of an inverted phase contrast microscope fitted with a thermoelectric chamber to hold and cool the culture dishes. Most of the experiments were done at a low temperature of $10-17^{\circ} \mathrm{C}$ (average, $13 \cdot 1^{\circ} \mathrm{C}$ ). Additional experiments were done at room temperatures (average, $22.1^{\circ} \mathrm{C}$ ). The bathing solution was a frog Ringer (115 mM NaCl, 2.5 mM KCl, $1.8 \mathrm{~mm} \mathrm{CaCl}_{2}, 4.0 \mathrm{~mm}$ HEPES $\mathrm{NaOH}, \mathrm{pH}$ 7.4) with $10^{-7} \mathrm{gm} / \mathrm{ml}$ TTX. The recording patch pipette contained either 500 or $50 \mathrm{~nm}$ ACh dissolved in the bath solution. Early experiments were performed using a home-made patch-clamp amplifier, with a feedback resistor of 1 or $10 \mathrm{G}$. Later we used a List EPC-7 amplifier with a $50 \mathrm{G} \Omega$ feedback resistor. The recording frequency was limited by a low-pass filter (8-pole Bessel) with a $3 \mathrm{~dB}$ cut-off frequency of $2 \mathrm{kHz}$ (or $4 \mathrm{kHz}$ in some of the experiments at room temperature), and the data were stored on an FM tape (Racal Store-4) for subsequent retricval and analysis. The overall rise time (from 10 to $90 \%$ level) of our recording system was $180 \mu \mathrm{sec}$ with the $2 \mathrm{kHz}$ filter setting. Except for several initial experiments in which data were hand-digitized, all the single-channel analysis was done using a set of minicomputer-based (PDP-11/03 or 11/23) programs developed in our laboratory, as outlined below.

Data analysis. The single-channel current records were digitized from FM tape at $10 \mathrm{kHz}$ (or $20 \mathrm{kHz}$ in some of the warm experiments), and dumped to a 30 megabyte Winchester disk (DSD 880) using a fast disk access routine kindly supplied by Dr. A. M. Brown. The data were then displayed in sequential blocks of 4096 points each on a CRT oscilloscope and inspected by the experimenter. During the inspection process, the program would (1) automatically compensate for slow baseline drifts, (2) determine the threshold levels for single-channel events automatically or manually (the threshold level was chosen approximately at the midpoint between the base line and the channel opening levels), and (3) allow the operator to eliminate sections of data containing obvious artifacts (see Sachs et al., 1982). Following the inspection process, an automatic event detection program constructed an idealized record of the data. The detection program was capable of analyzing records in which 2 events overlapped in time. We defined a closing shorter than $1 \mathrm{msec}$ as a gap, and a succession of openings separated by such gaps was treated as one event (or burst; more about this in Results). Histograms of current amplitudes and burst lengths were constructed from the idealized records.
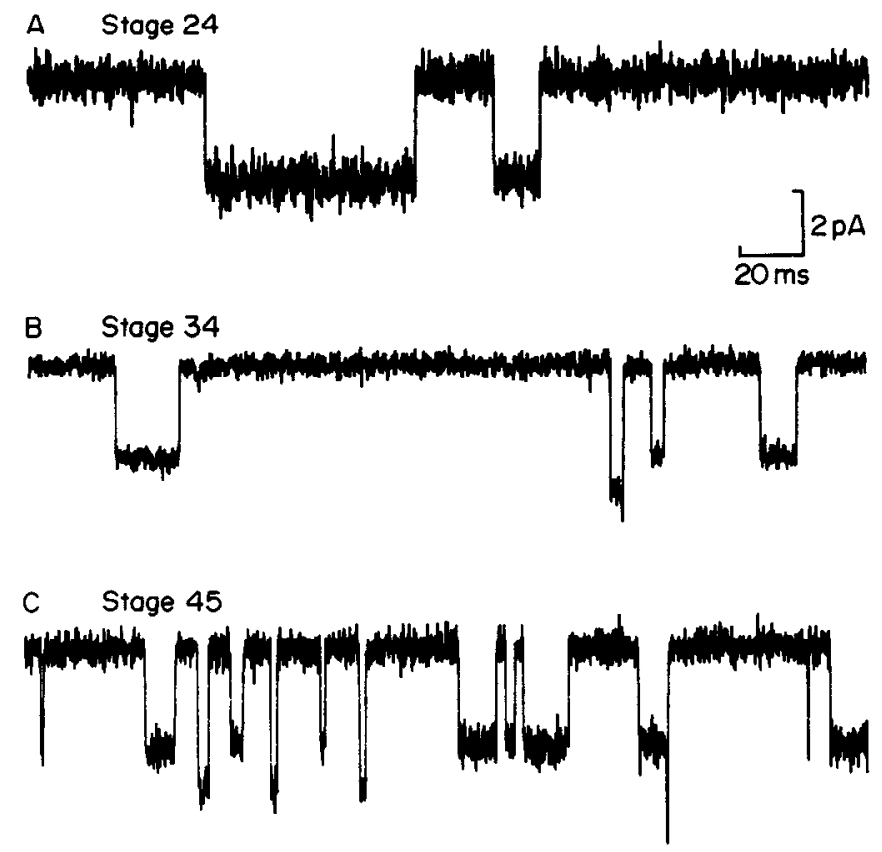

Figure 1. Examples of ACh-activated single-channel currents measured from 3 cells at different stages of development in vitro. Concentration of $\mathrm{ACh}$ was $500 \mathrm{~nm}$. Records were obtained from digitized data. Data were taken from cell-attached patches with a holding potential of $50 \mathrm{mV}$ hyperpolarized from resting potential. Inward currents are downward deflections. Note the existence of 2 types of events with different amplitudes at stages 34 and 45 . Data were low-pass-filtered at $2 \mathrm{kHz}$ $(-3 \mathrm{~dB})$ by an 8 -pole Bessel filter and digitized at $10 \mathrm{kHz}$. Recorded at temperatures of $13 \pm 2^{\circ} \mathrm{C}$.

\section{Results}

\section{$T$ wo classes of $A C h R$}

The functional development of AChRs of Xenopus muscle cells in culture was studied by Bridgman et al. (1984) by measuring macroscopic sensitivity to electrophoretically applied ACh. They reported that sensitivity to $\mathrm{ACh}$ emerges around developmental stage 20 , in agreement with the in vivo data from Blackshaw and Warner (1976). Macroscopic sensitivity gradually increases, probably due to an increase in the density of AChRs, reaching a plateau level at $1 \mathrm{~d}$ in culture. The half-life of degradation of AChRs in cultured Xenopus myocytes is $\sim 50 \mathrm{hr}$ (Brehm et al., 1983). Therefore, we can regard surface AChR molecules at stages 21-24 (which is within $5 \mathrm{hr}$ of the first emergence of AChRs) to be very young in both a metabolic and ontogenetic sense.

Figure 1 illustrates $\mathrm{ACh}$-induced single-channel currents recorded from 3 Xenopus muscle cells in culture at different developmental stages. The records were obtained at a potential 50 $\mathrm{mV}$ more hyperpolarized than the resting potential at a temperature of $\sim 13^{\circ} \mathrm{C}$. Recordings made at early stages (stages $21-$ 24) sometimes failed to display any channel activity. This is not surprising, since at these early stages macroscopic ACh sensitivity is low (Bridgman et al., 1984). Among patches that expressed channel activity at such early stages (Fig. $1 A$ ), we often obtained records of only one class of ACh-induced events with an average unitary conductance of $\sim 27 \mathrm{pS}$. Sometimes 2 classes of events were recorded, one with a unitary conductance of $\sim 27$ pS (referred to as the low-conductance, or low-g, channels) and the other with a conductance of $\sim 43 \mathrm{pS}$ at $13^{\circ} \mathrm{C}$ (referred to as the high-conductance, or the high-g, channels). After a day in 
Figure 2. Analysis of single-channel currents from 3 cells at different stages of development in vitro. ACh concentration $500 \mathrm{nM}$. Data were from same cells as in Figurc 1. Each row contains the data from one cell at the indicated developmental stage. All data are from cell-attached patches with a holding potential of $50 \mathrm{mV}$ hyperpolarized from resting potential. First column $(A I-C I)$ shows amplitude histograms of AChactivated single-channel currents. Only channel events with a duration of 400 $\mu \mathrm{sec}$ or greater were included in the analysis. Middle column $(A 2-C 2)$ shows the distribution of burst durations of low-conductance events. Third column (A3-C3) contains the distributions of burst durations of high-conductance events. $n$ indicates the number of events comprising each distribution. Ordinate (frequency) of each histogram is the percentage of the total distribution (namely, both low- and high-g events) contained in each bin. The windows for discriminating the low- and high-conductance channels were as follows: $A 2$, $2.5-4.0 \mathrm{pA} ; A 3,4.0-5.0 \mathrm{pA} ; B 2,2.0-$ $3.5 \mathrm{pA} ; B 3,3.5-5.0 \mathrm{pA} ; C 2,2.5-3.5 \mathrm{pA}$ $C, 3.5-5.0 \mathrm{pA}$. Temperature, $13 \pm 2^{\circ} \mathrm{C}$.

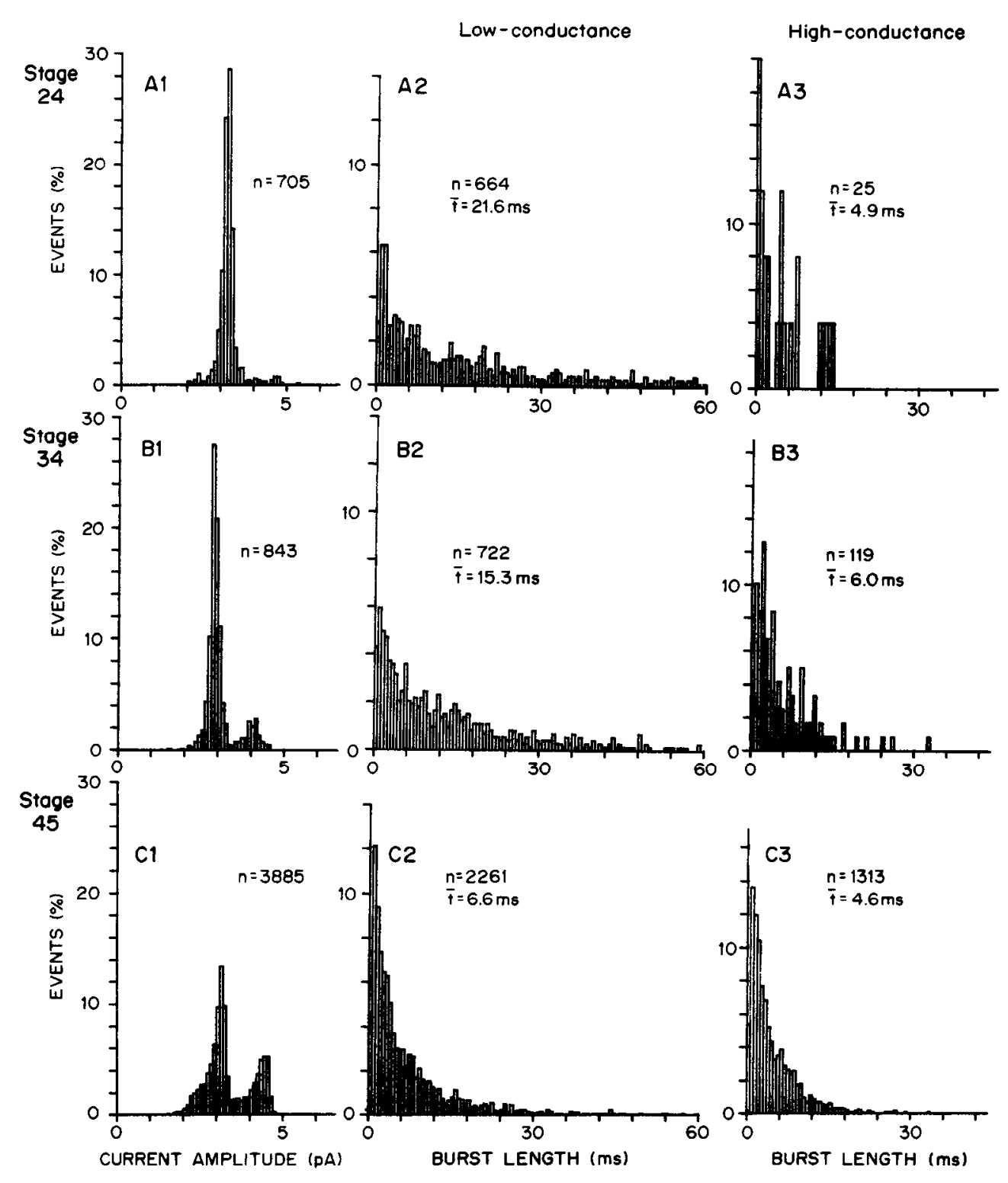

culture, ACh-induced single-channel currents were recorded in almost all cells, and usually both classes of channel were present. Examples of such $\mathrm{ACh}$-induced openings are shown in Figure $1 B$ (stage 34 ) and $1 C$ (stage 45 ), in which 2 classes of events are clearly seen. Although not visible in the records of Figure 1, we observed very short closings (gaps) similar to those described by Colquhoun and Sakmann (1985). We defined any openings separated by closed times shorter than $1 \mathrm{msec}$ as one event. As will be discussed later, this "event" probably corresponds to the "burst" of Colquhoun and Sakmann (1985).

The first column of Figure $2(A I-C I)$ shows amplitude histograms of single-channel currents at 3 developmental stages (stages 24, 34, and 45). The data were taken from the same cells as in Figure 1. There are 2 peaks in the distributions of event amplitudes. We set 2 discriminating windows in the amplitude distributions (see the legend of Fig. 2) and categorized events as arising from low- or high-g channels. In Figure 3, we plotted the number of high-g events relative to the total number of events against developmental "stage." It can be seen that the proportion of occurrence of high-g events increases gradually from an initial value of $\sim 5 \%$ at stages $21-24$ to a level of $\sim 50 \%$ at stages 44-47.

Very rarely, a third class of channels with a conductance of $<10 \mathrm{pS}$ was observed (also described by Brehm et al., 1984), but we did not do a systematic analysis on these events. Substates of channel openings (namely, a partial return from the open state; Hamill and Sakmann, 1981) were very rare in our preparation, in agreement with Brehm et al., (1984).

\section{Developmental changes of burst length}

The records of Figure 1 clearly show that the burst length of low-g events at early stages are much longer than those at later stages. The second and third columns of Figure 2 show burst length histograms for low- and high-g channels, respectively. In Figure $4 A$, average values of mean burst lengths $(\bar{t})$ are plotted over the period from stage 21 to stage 47 for the 2 classes of channel. The mean burst length $(\bar{t})$ of low-g channels underwent a marked developmental change (white columns, Fig. $4 A$ ), decreasing from an average value of $22 \mathrm{msec}$ at stages $21-24$ to a value of $6 \mathrm{msec}$ at stages $44-47$. The time course of this change 


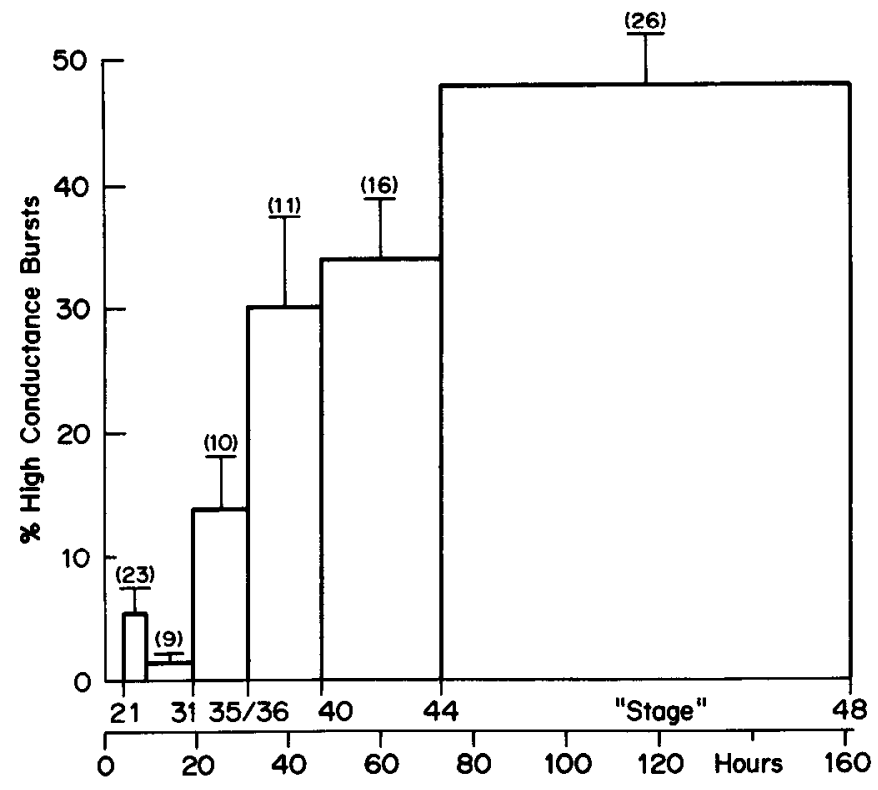

Figure 3. Proportion of high-conductance channels against developmental "stage." Data were obtained at $50 \mathrm{mV}$ hyperpolarized from resting potential. The number of high-conductance events was obtained as a percentage of the total number of events. Data included the patches that exhibited only one class (low-g) of channels (namely, zero percentage of high-g channels). See Figure 2 legend for examples of amplitude window setting. Number of cells in parentheses. Vertical bars indicate SEM. Groupings were stages 21-24, stages 25-30, stages 3134 , stages $35-39$, stages $40-43$, and stages $40-47$. Two cells at the beginning of stage 48 were included in the stage 47 category. We expressed the developmental stage of cultured muscle cells as "stage" (abscissa), which corresponds to the developmental stage of the sister embryos. This is because we did not always start cultures at exactly the same stage, nor did we keep all the cultures at exactly the same temperature (see Materials and Methods). The linear abscissa gives the time after stage 18 according to Nieuwkoop and Faber (1967). This would correspond to the culture time if all the cultures were started (plated) exactly at stage 18 and were kept always at $22-24^{\circ} \mathrm{C}$. This linear abscissa is convenient to compare our data with those of others. All physiological experiments of this figure were done at $13 \pm 2^{\circ} \mathrm{C}$.

was quite rapid, with $60 \%$ of the reduction taking place during the first $24 \mathrm{hr}$ in culture. In contrast, the mean burst length of the high-g channels did not seem to change during development (Fig. $4 A$, shaded columns); the average value of the large-g burst length at all stages was $5.0 \mathrm{msec}$.

While Figure $4 A$ illustrates the effect of development on the burst duration of the low-g channels, it does not distinguish between cells that exhibited both AChR types and those expressing only the low-g type. We wanted to be sure that events recorded from patches exhibiting only the low-g receptors were not qualitatively different from those exhibiting a heterogeneous population. We therefore calculated the ratio of mean burst lengths of the low-g and high-g for each patch that expressed both classes of AChR. As shown in Figure $4 B$, this value $\left(\bar{t}_{\text {low }} /\right.$ $\left.\bar{t}_{\text {high }}\right)$ was approximately 4 at stages $21-24$ and decreased to a level of $\sim 1.5$ by stages $44-47$, in agreement with the conclusion derived from Figure $4 A$.

\section{$\alpha$-Bungarotoxin control}

Control experiments were performed in order to ascertain that the channel events we recorded were, in fact, from AChRs. For these experiments, $\alpha$-Bungarotoxin was added to the bathing
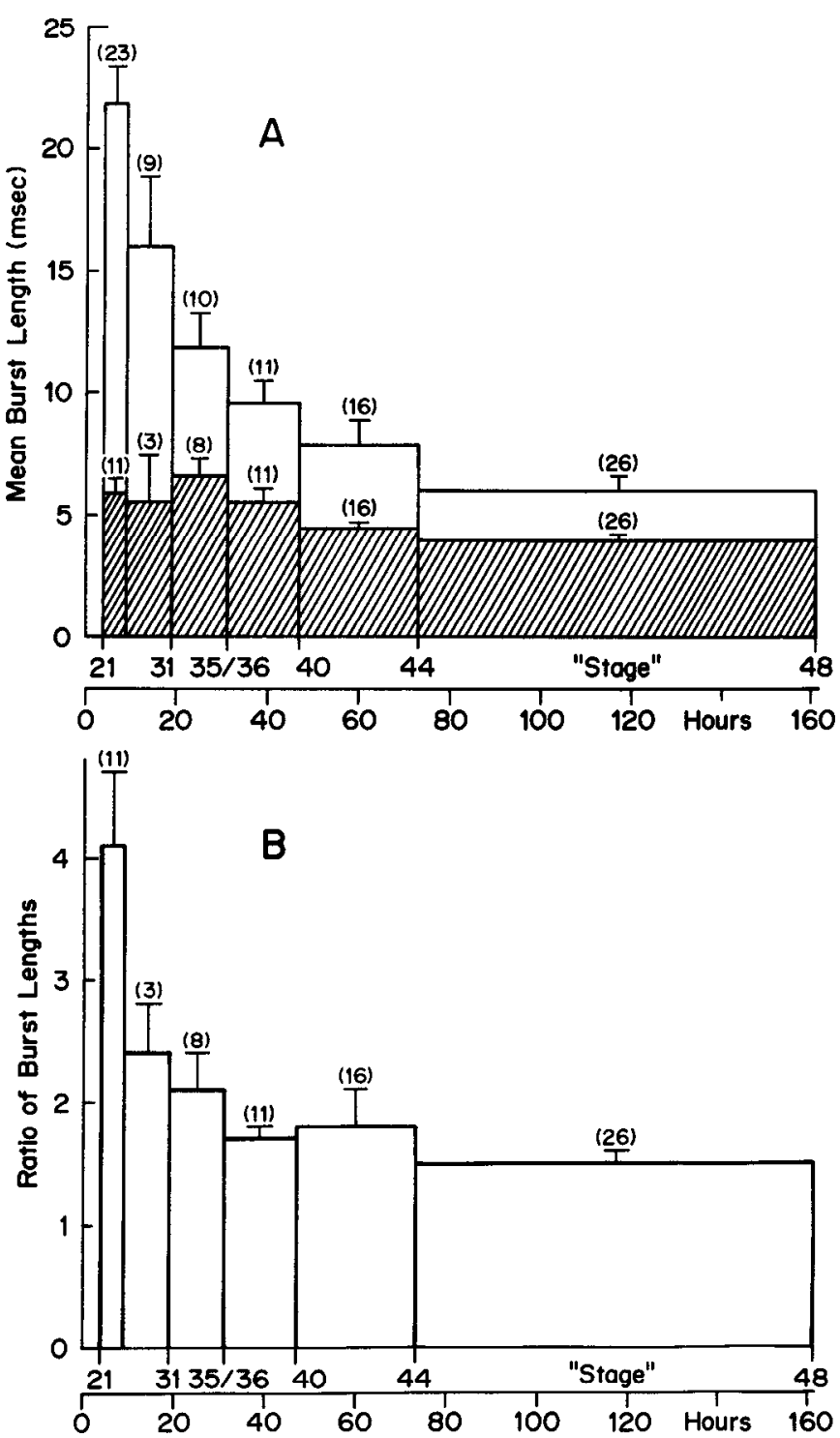

Figure 4. A, Mean burst lengths of low-conductance channels (open columns, including the shaded areas) and high-conductance channels (shaded columns alone) as a function of development in vitro. The data were obtained at a holding potential of $-50 \mathrm{mV}$ from rest. Groupings of the data by stage were as described in legend to Figure 3 . Numbers in parentheses indicate number of cells. Vertical bars indicate SEM. The linear abscissa gives the time after stage 18 . The "stage" marks indicate the developmental stage of sister embryos. All experiments at $13 \pm 2^{\circ} \mathrm{C}$. $B$, Ratio of burst lengths of low- and high-conductance events. The data are from a subset of data in $A$ : Only the cells exhibiting both low- and high-conductance events have been included. The ordinate $\left(\bar{t}_{\text {low }} / \bar{t}_{\text {high }}\right)$ is the ratio of mean burst lengths of the low- and high-g channels from a single patch. Holding potential, $-50 \mathrm{mV}$ from rest.

solution (final concentration, $0.5 \mu \mathrm{M}$ ), as well as to the patch pipette prior to recording.

Patch-clamp records were obtained from 8 cells at stages $23-$ 27 and from 3 cells at stage 47 . Ten of these 11 cells exhibited no channel events resembling those elicited by ACh. In one cell we recorded channel events of the same magnitude as our typical channels. However, these events looked ragged and flickered. The conductance was $\sim 35 \mathrm{pS}$, and the reversal potential was $30 \mathrm{mV}$ depolarized from rest. These channels could correspond to the flicker channel (F-channels) that Guharay and Sachs (1984) 

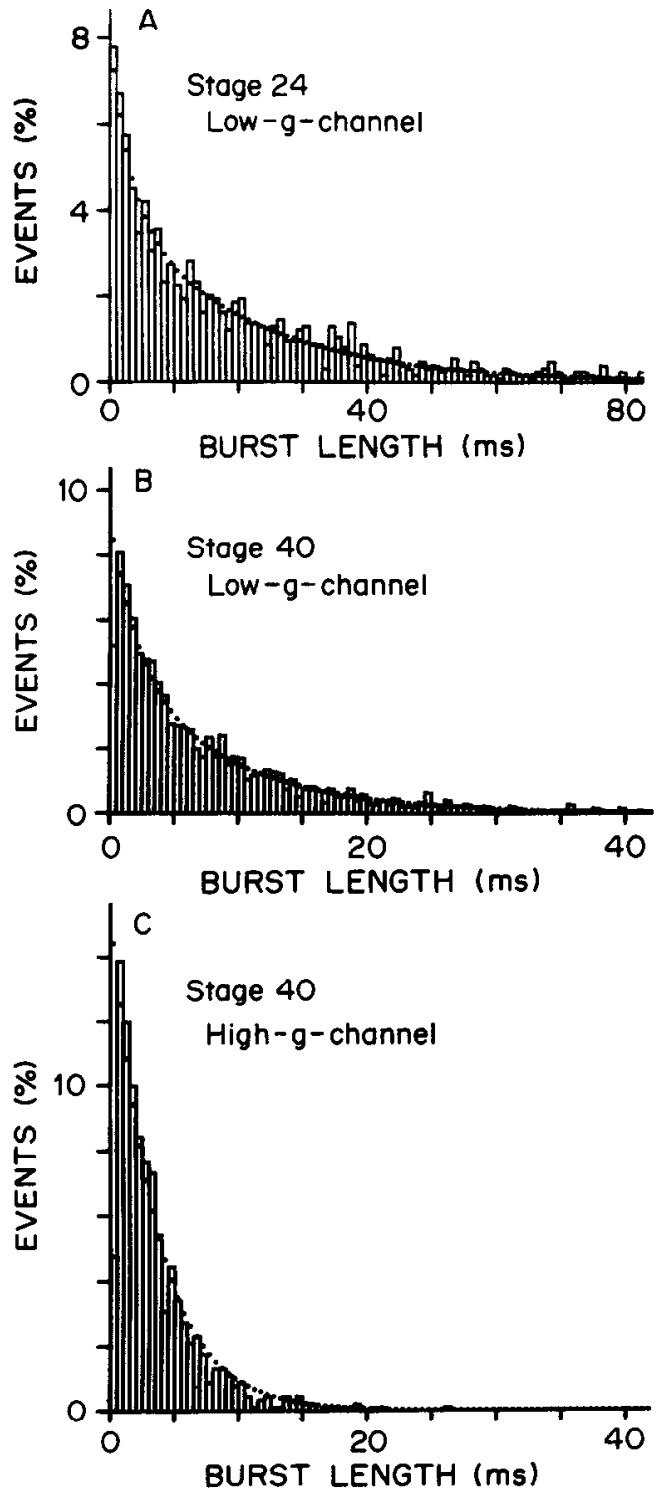

Figure 5. Burst length histograms fit to the sum of 2 exponentials: $a_{1} \exp \left(-t / \tau_{1}\right)+a_{2} \exp \left(-t / \tau^{2}\right)$. The ordinate is events (per bin) as percentage of the total events (namely, total of both low- and high-g events). Only channel events with a duration of $400 \mu \mathrm{sec}$ or greater were included. The fitting was done by stripping and successive determination of the slow and fast components without constraining the value of the area. Therefore, it is not a probability density function. $A$, Stage 24 , low-g channel, $n=1233, \tau_{1}=3.26 \mathrm{msec}, \tau_{2}=20.4 \mathrm{msec}$. The area of fast component, $a_{1} \tau_{1}=12.9 \%$ of the total area for the low-g channel; $t$ (mean burst length) $=20.0 \mathrm{msec}$; temperature, $11.5^{\circ} \mathrm{C}$. $B$, Stage 40 , low-g channel, $n=1694, \tau_{1}=2.14 \mathrm{msec}, \tau_{2}=8.75 \mathrm{msec}$. The area of fast component, $a_{1} \tau_{1}=19.3 \%$ of the total area for the low-g channels; $\bar{t}=$ $8.00 \mathrm{msec}$; temperature $=12.8^{\circ} \mathrm{C}$. C, Stage 40 , high-g channel, $n=901$, $\tau_{1}=3.32 \mathrm{msec}, \tau_{2}=4.67 \mathrm{msec}$. The area of fast component, $a_{1} \tau_{1}=$ $12.9 \%$ of the total area for the high-g channel; $\bar{t}=3.59 \mathrm{msec}$; temperature, $12.8^{\circ} \mathrm{C}$.

described. Since the occurrence of these channels was rare and since these channels can bc differentiated by inspection, it is very unlikely that they have influenced our results on $\mathrm{AChR}$ channels.

\section{Gap threshold}

According to the model of Colquhoun and Sakmann (1985), the distribution of closed times of ACh-activated channels in frog muscle endplate has 2 main components, a very fast one with an average of $<100 \mu \mathrm{sec}$, and a much longer component representing the real closing (in addition to a minor intermediate component). The fast component (gap) was interpreted as representing the closed receptor with agonists still attached.

Similar gaps were observed in the present records of Xenopus AChRs in culture (for example, see Fig. 8, stage 44 of the present paper; or Igusa and Kidokoro, 1987). Although we have not investigated the distribution of closed time in the present study, we have, somewhat arbitrarily, defined the gap threshold at 1 $\mathrm{msec}$, and a series of openings separated by gaps was treated as one event. In order to test the validity of this procedure, we investigated the effect of varying the gap threshold on the length of the event. We found that for low-conductance channels at stage 24, the mean event duration with a gap threshold of 0.2 msec was $6 \pm 0.4 \%$ (mean \pm SEM, 5 cells) less than that with the gap threshold of $1 \mathrm{msec}$, whereas it became $1.6 \pm 0.4 \%$ longer when the gap threshold was changed from 1 to $2 \mathrm{msec}$. For low-conductance channels at stages $40-44$, the corresponding values were $4.4 \pm 0.5 \%$ less and $3.9 \pm 0.8 \%$ more, whereas for high-conductance channels at stages $40-44$, they were 8.1 $\pm 2.3 \%$ less and $6.2 \pm 1.5 \%$ more, respectively. It is, therefore, likely that the gap length is very fast (on the order of $100 \mu \mathrm{sec}$ or less) compared with the average closed time, and therefore the burst length is relatively insensitive to the choice of the gap threshold so long as it is about $1 \mathrm{msec}$. [In fact, the data of Igusa and Kidokoro (1987) suggest the presence of a very fast component.] Thus, our event duration is probably close to the real burst length (particularly in the low-g channels).

\section{Exponential fit of burst length}

The total number of channel events recorded from patches at early stages was often low (the average number of events recorded for the cells of stages 21-24 was 293 at $50 \mathrm{mV}$ hyperpolarized potential), probably because the number of channels in the patch is small at these stages, and also because the channels tended to desensitize after 5-10 $\mathrm{min}$ in the presence of 0.5 $\mu \mathrm{M}$ ACh. Furthermore, the frequency of occurrence of high-g events is very low at early stages. These circumstances prevented us from analyzing the burst length distributions by curve-fitting procedures. We simply characterized the channel durations by the mean burst length $(\bar{t})$.

To test whether this procedure was justifiable, we selected for curve fitting those patches in which a large number of events $(>650)$ were obtained for a given class of channels. As shown in the examples of Figure 5, the burst length distributions of both low-g channels (stages 24 and 40) and high-g channels (stage 40 ) could each be fit by a sum of 2 exponentials, in agreement with the data of AChRs in other preparations (Jackson et al., 1983; Sine and Steinbach, 1984; Colquhoun and Sakmann, 1985). Table 1 lists the 2 time constants $\left(\tau_{1}\right.$ and $\left.\tau_{2}\right)$ of these exponentials and the fractional area of the fast component $\left(a_{1} \tau_{1}\right)$, together with the values of mean burst length $(\bar{t})$. As shown in Table 1, the values of the slow time constants $\left(\tau_{2}\right)$ approximately equal the mean burst length $(\bar{t})$ in both classes of channels. In the case of low-g channels, the 2 time constants are well separated $\left(\tau_{2}\right.$ is 7 times larger than $\left.\tau_{1}\right)$. However, in high-g channels, the 2 time constants are not very different, suggesting that one time constant could also produce a fairly good fit. These results are in rough agreement with the data of Igusa and Kidokoro (1987), who observed the presence of 2 time constants in low-g channels only. 
Table 1. Comparison of mean burst length and time constants at low temperature

\begin{tabular}{|c|c|c|c|c|c|c|c|}
\hline $\begin{array}{l}\text { Channel } \\
\text { type }\end{array}$ & Stage & $n$ & $\begin{array}{l}\tau_{1} \\
\text { (msec) }\end{array}$ & $\begin{array}{l}\tau_{2} \\
\text { (msec) }\end{array}$ & $\begin{array}{l}a_{1} \tau_{1} \\
(\%)\end{array}$ & $\bar{t}$ (msec) & $\tau_{2} / \bar{t}$ \\
\hline \multirow[t]{2}{*}{ Low-g } & $24-30$ & 8 & $2.0 \pm 0.28$ & $14.9 \pm 1.8$ & $15.0 \pm 1.8$ & $14.8 \pm 1.7$ & $1.0 \pm 0.02$ \\
\hline & $40-48$ & 14 & $0.92 \pm 1.0$ & $6.9 \pm 1.1$ & $23.8 \pm 2.9$ & $7.1 \pm 1.0$ & $0.9 \pm 0.04$ \\
\hline High-g & $40-48$ & 6 & $3.9 \pm 0.7$ & $5.5 \pm 0.5$ & & $4.8 \pm 0.3$ & $1.1 \pm 0.08$ \\
\hline
\end{tabular}

Data are mean \pm SEM. All data are from experiments at $-50 \mathrm{mV}$ from rest at $\sim 13^{\circ} \mathrm{C}$. $n$, number of cells analyzed. $\tau_{1}$ and $\tau_{2}$, fast and slow time constants of the burst length distribution; $a_{1} \tau_{1}$, area of fast time constant events in relationship with the total area for low-g channels; $\bar{t}$, mean burst length. Only records with more than 650 events were analyzed.

The data in Table 1 were obtained at low temperatures $\left(\sim 13^{\circ} \mathrm{C}\right)$. Similar analyses were done for the data obtained at room temperatures $\left(\sim 22^{\circ} \mathrm{C}\right)$, and again the ratios of $\bar{t}$ and $\tau_{2}$ were approximately unity $(0.97-1.23)$. These results indicate that we can regard our mean burst length $(\bar{t})$ as reflecting the major time constant (the slower component) of burst length histograms.

\section{Unitary channel conductance and reversal potential}

Unitary conductances were measured by recording channel events at various patch potentials (Fig. 6). Table 2, which gives a summary of the data, shows that neither the single-channel conductance nor the reversal potential of either class of channel seems to change during development. Since the "reversal potential" in Table 2 is a relative value from the resting potential, the fair constancy of this value during development suggests either (1) that the resting potential and reversal potential change in the same direction by the same amount or (2) that neither resting potential not reversal potential changes during development. We prefer the second explanation because of its simplicity.

Table 2 also indicates that the reversal potential for the low-g channel is consistently larger than that of high-g channels. Since the resting potential of our cultured cells measured by microelectrode was $78 \mathrm{mV}$ (average of 31 cells; Greenberg et al., 1985), the average value of reversal potential would have been $-8 \mathrm{mV}$ $(-78+70 \mathrm{mV})$ for low-g channels and $-20 \mathrm{mV}(-78+58$ $\mathrm{mV}$ ) for high-g channels. These results suggest a possibility that the ratio of $\mathrm{Na}^{+}$to $\mathrm{K}^{+}$permeability may be slightly different between the 2 classes of channels; but the difference might have originated from systematic errors. In estimating the reversal potential, we used extrapolation from data taken over a hyperpolarized potential range (up to $200 \mathrm{mV}$ in absolute potential).
The current-voltage relationship appeared linear over this potential range even for patches in which currents were recorded at 6 voltages (but see Brehm et al., 1984). Any nonlinearity that might be present over the voltage range near the reversal potential, however, would produce a substantial error in our estimate of the reversal potential.

\section{Voltage dependence of channel burst length}

Channel burst lengths of AChRs are known to be influenced by the transmembrane voltage, with hyperpolarization producing longer events (Magleby and Stevens, 1972). Thus, the developmental change that we observed in the mean burst length of the low-g channels could arise from development changes in voltage dependence. As can be seen from the 2 examples in Figure 7 , as well as from the summary in Table 3, neither class of AChRs exhibited any developmental changes in the voltage dependence of burst length. Nor was there any significant difference in the voltage dependence between the 2 classes of channels ( 78 versus $74 \mathrm{mV}$ for $e$-fold changes).

\section{Temperature effects}

Our single-channel data so far described were obtained at cold temperatures $\left(\sim 13^{\circ} \mathrm{C}\right)$. This was necessary to measure the channel burst lengths more reliably. Studies by other investigators using the same system (Brehm et al., 1984; Igusa and Kidokoro, 1987), however, were carried out at room temperatures. To facilitate direct comparison of our results with those of others, we repeated some of our experiments at room temperatures.

Records in Figure 8 show ACh-induced currents at $22^{\circ} \mathrm{C}$ from 2 cells at early (stage 22) and late (stage 44) stages, and the histograms of Figure 8 present analysis of the complete data from these cells. Table 4 summarizes the data at room tem-

Table 2. Unitary conductance and reversal potential

\begin{tabular}{|c|c|c|c|c|c|c|}
\hline \multirow[b]{2}{*}{ Stage } & \multicolumn{3}{|c|}{ Low-conductance } & \multicolumn{3}{|c|}{ High-conductance } \\
\hline & $n$ & $\begin{array}{l}\gamma \\
(\mathrm{pS}) \\
\end{array}$ & $\begin{array}{l}\text { Reversal } \\
\text { potential } \\
(\mathrm{mV})\end{array}$ & $n$ & $\begin{array}{l}\gamma \\
(\mathrm{pS}) \\
\end{array}$ & $\begin{array}{l}\text { Reversal } \\
\text { potential } \\
(\mathrm{mV})\end{array}$ \\
\hline $21-24$ & 19 & $25.4 \pm 1.3$ & $80.9 \pm 7.1$ & 7 & $47.1 \pm 4.4$ & $53.3 \pm 8.2$ \\
\hline $25-30$ & 12 & $27.8 \pm 1.6$ & $71.3 \pm 6.6$ & 5 & $44.1 \pm 1.6$ & $52.9 \pm 5.6$ \\
\hline $31-34$ & 6 & $27.0 \pm 1.9$ & $60.7 \pm 7.2$ & 6 & $39.2 \pm 1.7$ & $56.6 \pm 8.9$ \\
\hline $35-39$ & 11 & $31.2 \pm 1.1$ & $58.1 \pm 5.3$ & 11 & $47.3 \pm 2.2$ & $49.5 \pm 5.6$ \\
\hline $40-43$ & 15 & $29.2 \pm 1.1$ & $64.8 \pm 4.9$ & 15 & $42.7 \pm 0.9$ & $59.8 \pm 2.7$ \\
\hline $44-48$ & 23 & $25.8 \pm 1.3$ & $71.7 \pm 4.3$ & 23 & $39.3 \pm 1.5$ & $62.8 \pm 3.2$ \\
\hline Total & 86 & $27.4 \pm 0.6$ & $69.9 \pm 2.5$ & 67 & $42.5 \pm 0.9$ & $57.7 \pm 2.0$ \\
\hline
\end{tabular}

Values (means \pm SEM) are the unitary conductance $(\gamma)$ and reversal potential (relative to the resting potential) as obtained from regression analysis of mean amplitude of single-channel events. Only values from regressions with correlation coefficient $\geq 0.85$ were included. $n$, number of cells. Data were obtained at $\sim 13^{\circ} \mathrm{C}$. 


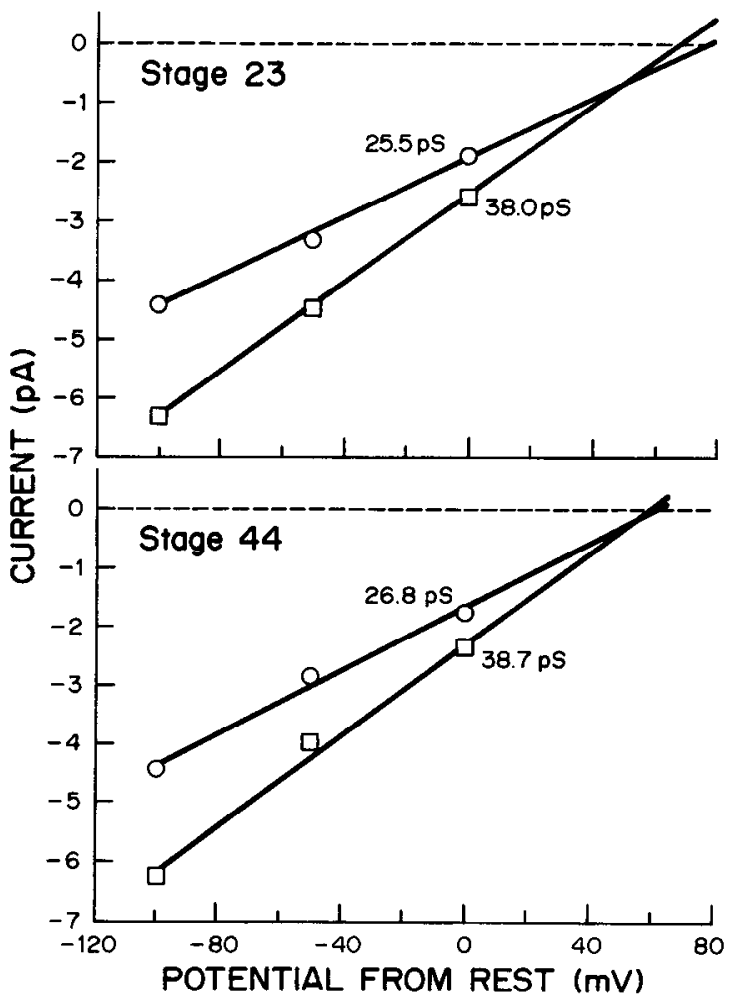

Figure 6. Unitary conductance of AChRs at 2 stages of development in vitro. ACh-induced single-channel currents were measured at resting potential, $-50 \mathrm{mV}$ from rest, and $-100 \mathrm{mV}$ from rest. The average current amplitudes for each of the 2 classes of AChR are plotted against holding potential. Upper graph, data from a cell at stage 23; lower graph; data from a cell at stage 44 . Indicated conductance values were obtained by linear regression. Temperature $13 \pm 2{ }^{\circ} \mathrm{C}$.

peratures and compares them with the data at cold temperatures. As seen from Table 4, at room temperatures the mean burst length of the low-g channels at stages $21-24(6.7 \mathrm{msec})$ was 3.4 timcs longer than that at stages $40-48$, in agreement with the results at low temperatures. The $Q_{10}$ of the burst lengths was calculated for the low-g channels at early stages and for both low- and high-g channels at late stages. The values obtained $\left(Q_{10} 2.5-4.1\right)$ are in agreement with the data from adult muscles (see Peper et al., 1982).

Single-channel conductances were 44 pS (low-g channels) and

Table 3. Voltage dependence of mean burst length

\begin{tabular}{lrlrcl} 
& \multicolumn{2}{c}{ Low-conductance } & & \multicolumn{2}{c}{ High-conductance } \\
\cline { 2 - 3 } Stage & $n$ & $\begin{array}{l}\text { e-fold change } \\
(\mathrm{mV})\end{array}$ & & $\begin{array}{l}e \text {-fold change } \\
(\mathrm{mV})\end{array}$ \\
\hline $21-24$ & 18 & $91.6 \pm 9.4$ & 6 & $90.3 \pm 21.2$ \\
$25-30$ & 12 & $71.2 \pm 4.0$ & 5 & $57.6 \pm 6.3$ \\
$31-34$ & 5 & $95.5 \pm 24.3$ & 6 & $61.2 \pm 3.9$ \\
$35-39$ & 7 & $67.4 \pm 3.5$ & 9 & $82.0 \pm 7.6$ \\
$40-43$ & 14 & $68.5 \pm 6.4$ & 14 & $64.0 \pm 2.8$ \\
$44-48$ & 17 & $74.3 \pm 6.5$ & 23 & $78.8 \pm 4.4$ \\
Total & 73 & $77.7 \pm 3.6$ & 63 & $73.7 \pm 3.1$
\end{tabular}

Values (mean $\pm \mathrm{SEM}$ ) are the change in potential (mV) that produced an $e$-fold change in mean burst length, based on a log-linear regression. Only values from regressions with a correlation coefficient $\geq 0.85$ were included. Data were obtained at $\sim 13^{\circ} \mathrm{C}$.

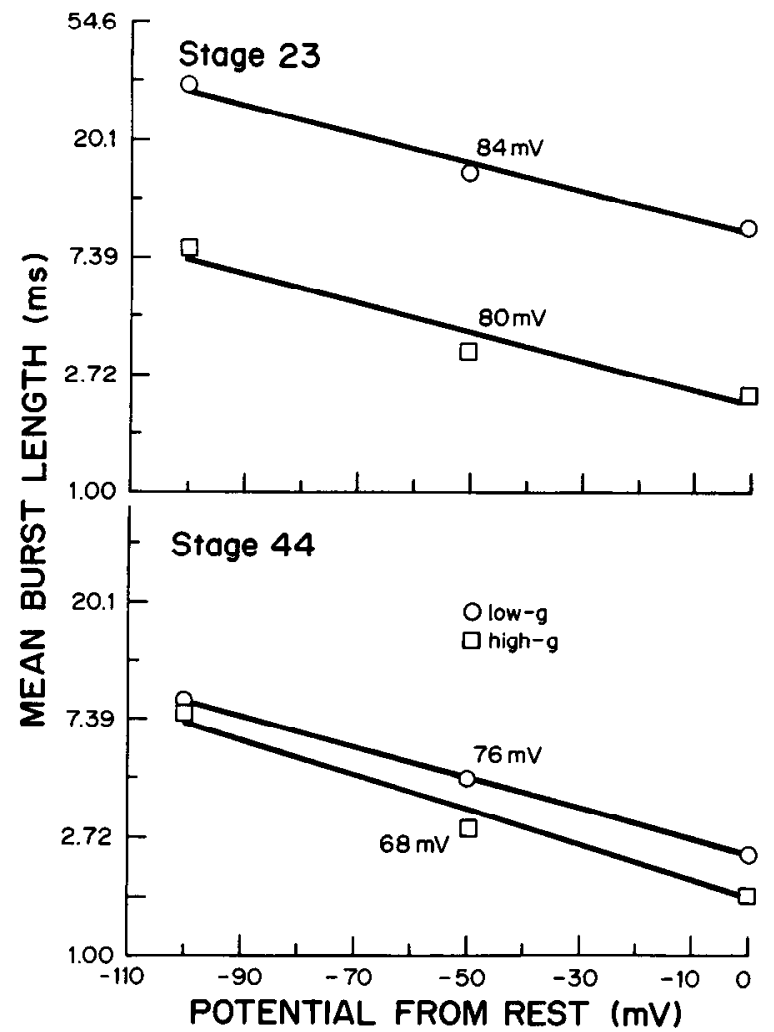

Figure 7. Voltage dependence of AChR mean burst length at 2 stages of development in vitro. The mean burst length for each of the 2 classes are plotted against holding potential. Note the semilogarithmic scale. Data are from the cells in Figure 6 . The values indicated are the potential required for an $e$-fold change in burst length. Temperature, $13 \pm 2^{\circ} \mathrm{C}$.

$73 \mathrm{pS}$ (high-g channels) at $22^{\circ} \mathrm{C}$. These values are close to those reported by other investigators (Brehm et al., 1984; Igusa and Kidokoro, 1987). Comparison of high-temperature data with the low-temperature data gives a $Q_{10}$ of 1.7-1.9 for channel conductance (Table 4).

\section{Low agonist concentration}

Almost all the data presented in this paper were obtained using an $\mathrm{ACh}$ concentration of $500 \mathrm{~nm}$ in the patch pipette. With this concentration, the frequency of single-channel events tended to decline gradually over experimental periods lasting more than 10 min, probably due to desensitization. One possible criticism of our experiments would be that our data were obtained for AChRs that had been partially desensitized. We therefore repeated some experiments ( 5 cells at stages $23-25$, and 7 cells at stage 44) with an ACh concentration of $50 \mathrm{nM}$. As expected, the event frequency was low at this ACh concentration, and in most cells no tendency toward desensitization was observed. No differences (even at $90 \%$ confidence level) in burst length or unitary conductance between high agonist experiments and low agonist experiments were observed. Accordingly, the low agonist data were added to the data pool used to construct summary figures and tables presented in this paper.

\section{Discussion}

One conclusion from the present experiments is that the relative frequency of high-conductance events increases gradually as development proceeds. It has been known for some time that the 


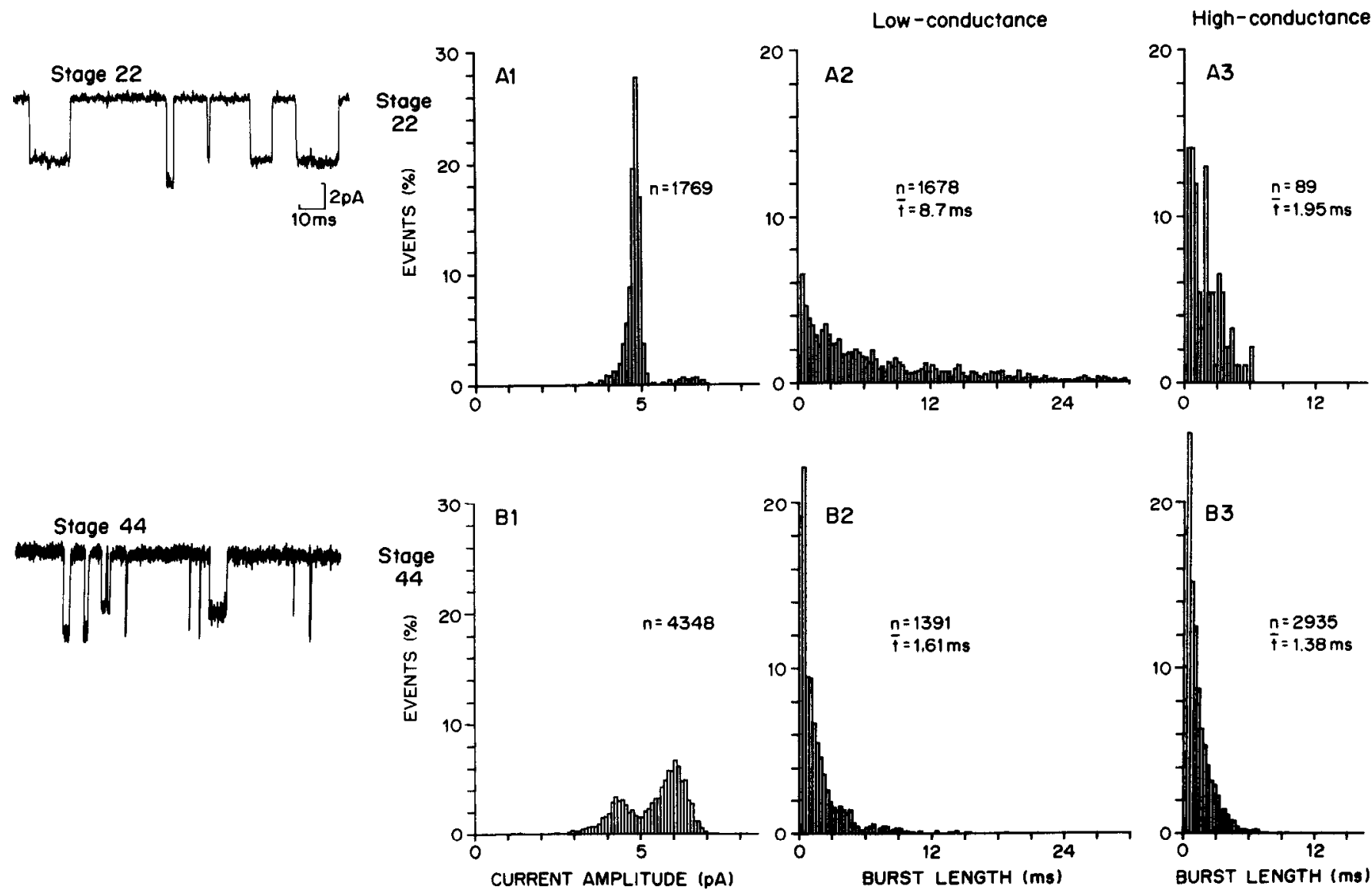

Figure 8. Left-hand side, ACh-induced single-channel currents recorded at room temperature at 2 developmental stages in vitro. Data were taken with a holding potential of $50 \mathrm{mV}$ hyperpolarized from rest. Inward currents are downward deflections. Data at stage $22 \mathrm{were}$ filtered at $2 \mathrm{kHz}$ $(-3 \mathrm{~dB})$ and digitized at $10 \mathrm{kHz}$, whereas data at stage 44 were filtered at $4 \mathrm{kHz}(-3 \mathrm{~dB})$ and digitized at $20 \mathrm{kHz}$. Histograms, Analysis of singlechannel currents recorded at room temperature. Row $A$, Data from the cell at stage 22 . Row B, Data from the cell at stage 44 . Both cells were hyperpolarized by $50 \mathrm{mV}$ from resting potential. The first column $(A 1, B 1)$ shows the distribution of current amplitudes of single-channel events. The second column $(A 2, B 2)$ shows the distribution of burst lengths for low-conductance channels. The third column $(A 3, B 3)$ shows the distribution of burst lengths for high-conductance channels. All channel events lasting longer than $200 \mu \mathrm{sec}$ were included in the analysis. $n$ indicates the number of events comprising each distribution. $\bar{t}$ indicates the mean burst length. Ordinate is the frequency of events contained in each bin as the percentage of the total events (total of both low- and high-g events). The windows for discriminating the 2 types of channels were as follows: $A 2,3.0-5.5 \mathrm{pA}$; $A 3,5.5-8.0 \mathrm{pA} ; B 2,2.0-5.0 \mathrm{pA} ; B 3,5.0-7.5 \mathrm{pA}$. Temperature, $22 \pm 1^{\circ} \mathrm{C}$.

Table 4. Temperature effects on mean burst length and unitary conductance

I. Mean burst length at $-50 \mathrm{mV}$ from rest (msec)

\begin{tabular}{|c|c|c|c|c|}
\hline \multirow[b]{2}{*}{ Stage } & \multicolumn{2}{|l|}{ Low temperature } & \multicolumn{2}{|c|}{ Room temperature } \\
\hline & Low-g & High-g & Low-g & High-g \\
\hline $21-24$ & $21.8 \pm 1.5(23)$ & $5.9 \pm 0.6(11)$ & $6.7 \pm 0.7(5)$ & $2.0 \quad(1)$ \\
\hline \multirow[t]{4}{*}{$40-48$} & $6.7 \pm 0.6$ & $4.2 \pm 0.2(42)$ & $2.0 \pm 0.3(10)$ & $1.9 \pm 0.2(10)$ \\
\hline & \multicolumn{4}{|c|}{ II. Unitary conductance (pS) } \\
\hline & \multicolumn{2}{|l|}{ Low temperature } & \multicolumn{2}{|c|}{ Room temperature } \\
\hline & Low-g & High-g & Low-g & High-g \\
\hline $21-48$ & $27.4 \pm 0.6(86)$ & $42.5 \pm 0.9(67)$ & $44.2 \pm 2.5(13)$ & $73.2 \pm 5.1(5)$ \\
\hline
\end{tabular}

$Q_{10}$ of mean burst length

\begin{tabular}{|c|c|c|c|c|c|}
\hline \multicolumn{3}{|c|}{ 等 } & \multicolumn{3}{|c|}{ - 10} \\
\hline Stage & Low-g & High-g & Stage & Low-g & High-g \\
\hline $21-24$ & 3.9 & - & $21-48$ & 1.7 & 1.9 \\
\hline $40-48$ & 4.1 & 2.5 & & & \\
\hline
\end{tabular}

Low temperature, $\sim 13^{\circ} \mathrm{C}$; room temperature, $\sim 22^{\circ} \mathrm{C}$. Values are means $\pm \mathrm{SEM}$, and number of cells is given in parentheses. 
kinetics of $\mathrm{AChRs}$ undergo a shift during synaptogenesis. Fischbach and Schuetze (1980) and Michler and Sakmann (1980) reported that the open time kinetics of AChRs in rat muscles, estimated from endplate currents or from current fluctuations, become faster during the first few weeks after birth. They suggested that this is caused by a relative increase in AChRs with fast kinetics. Kullberg et al. (1981) and Brehm et al. (1982) observed a similar phenomenon in Xenopus embryonic muscles in vivo and in vitro.

Subsequently, Siegelbaum et al. (1984), Brehm et al. (1984), and Leonard et al. (1984) used the patch-clamp technique on cultured muscles, directly observing single-channel behavior. These experiments revealed that there are 2 types of AChRs in embryonic muscles in culture and that the proportion of highconductance channels increases during development. The data of the present study, summarized in Figure 3, are more comprehensive than our early observations (Leonard et al., 1984) and extend the results of Brehm et al. (1984) by covering the period immediately after the first insertion of AChRs up to $7 \mathrm{~d}$ in culture. The data indicate that (1) immediately after the first emergence of AChRs, there already exist 2 types of AChRs in the membrane (in agreement with Greenberg et al., 1984); (2) the proportion of high-conductance channels is initially only a few percent, but increases gradually over the period of $7 \mathrm{~d}$; and (3) these changes occur without innervation.

As for the molecular mechanisms of this process of AChR maturation, Michler and Sakmann (1980) originally suggested that posttranslational or postinsertional (i.e., into the surface membrane) modification of AChR molecules could be responsible for the conversion from low- to high-conductance channels. No direct evidence exists to preclude this possibility. However, a recent study (Mishina et al., 1986) using recombinant DNA techniques indicates that the high- and low-conductance channels in bovine skeletal muscle are different at the subunit level, their $\gamma$-subunits arising from separate mRNAs. Thus, the increase in the proportion of high-conductance channels during development could simply be a reflection of a gradual addition of newly synthesized receptors of the high-conductance type. Recent data reported by Brehm et at. (1985) and Carlson et al. (1985), who used cycloheximide treatment of developing Xenopus muscle cells, are in agreement with this idea.

Our data reveal another developmental change of AChRs, namely, a marked change in the burst duration of low-conductance channels. The burst length of the low-g channel underwent an approximate 4-fold reduction during the first $3 \mathrm{~d}$ in culture. This change begins immediately after the first emergence of AChRs and is almost complete during the second day of culture. The timing of this change would correspond to the period during which functional and morphological changes take place rapidly in the neuromuscular junctions in vivo (Blackshaw and Warner, 1976; Kullberg et al., 1977). The developmental change is specific in the sense that it affects only the burst length of lowconductance channels, while other parameters such as unitary conductance, reversal potential, and the voltage dependence of burst length were stationary. There were no changes in the attributes of high-conductance channels. The shift in kinetics of the low-g channel must depend upon the developmental age of the muscle cells rather than the metabolic age of the receptors because Greenberg et al. (1985) showed that the gating properties of newly inserted AChRs (namely, metabolically new receptors) in mature cells did not differ from those of AChRs already present in the membrane.
We have examined this change as a developmental phenomenon without relating our data to a particular kinetic model. Thus, several biophysical questions remained unanswered. For example, we did not analyze closed times to determine whether the difference in burst lengths was due primarily to changes in $\alpha$ (the transition rate constant from open to closed state) or to changes in average numbers of openings per burst, which in turn is a function of $k_{2}$ and $\beta$ in Colquhoun and Sakmann's (1985) scheme. Also, our data suggest the existence of 2 kinds of open state, and analyzing these 2 states during early development may throw light on the detailed mechanisms of the receptor development. These questions can be answered by analyzing data obtained with a higher-frequency recording system than that used in the present experiment.

There are several molecular mechanisms that could account for the observed change in channel burst length during development. These mechanisms fall into 2 classes: extrinsic and intrinsic. An extrinsic mechanism is one in which the receptor behaves differently due to changes in its environment. An intrinsic mechanism pertains to a change in the molecular structure of the receptor. Extrinsic factors such as changes in membrane fluidity could influence channel gating, but probably not in such a specific fashion. For example, perturbations by feeding cholcstcrol to the membrane or changing its fluidity by halothane either produce no change in the gating behavior or affect the open time of both classes of channels (Steele et al., 1981; Fernández et al., 1982; Lechleiter and Gruener, 1984). Since the modulation we observed is confined to burst length of the low-conductance channel, it is unlikely that the modulation is caused by changes in the lipid environment. A more plausible external influence would be an interaction of the receptor with neighboring receptors or with another membrane constituent such as an associated protein or the cytoskeleton. Candidates for intrinsic mechanisms are changes at the level of posttranslational processing, such as glycosylation or phosphorylation. The nicotinic AChR is known to be a substrate for several kinases (Nestler et al., 1984), and Eusebi et al. (1987) recently reported that stimulation of C-kinase activity influences the gating and unitary conductance of AChR channels. Alternatively, the change in burst length could result from regulation at the transcriptional level. In fact, Mishina et al. (1986) mentioned a developmental reduction in the level of $\delta$-subunit message, without speculating on any functional changes.

One might ask whether the change in burst length is just an aberrant phenomenon confined to cultured Xenopus muscle cells. Recently, Owen and Kullberg (1986) reported a shortening of open times of low-conductance AChRs in Xenopus myotomes cells during development in vivo. Therefore, it is unlikely that our observation is an artifact derived from cell culture. Steele and Steinbach (1986) observed that there are 3 types of AChRs in mouse muscles: one type that corresponds to adult junctional receptors (high-conductance), another type corresponding to adult extrajunctional receptors (low-conductance), and a third type from embryonic muscle, having low conductance and long burst lengths. This suggests that the process we observe in Xenopus is not confined to one species of animal.

Finally, what are the functional advantages of having 2 classes of AChRs? Evidently the high-conductance channels mediate synaptic transmission. With their fast kinetics, they are wellsuited to the task of initiating fine, discriminating movements. The functional significance of low-conductance channels, on the other hand, is less clear. The role could be one of activity de- 
tection. AChRs are permeable to $\mathrm{Ca}^{2+}$ as well as $\mathrm{Na}^{+}$and $\mathrm{K}^{+}$. Entry of $\mathrm{Ca}^{2+}$ and $\mathrm{Na}^{+}$ions into the protoplasm may play important roles in proper development of muscle function (Schuctzc and Role, 1987; Kidokoro and Saito, 1987). In this case, the magnitude of ion translocation into the cell would be more important than the time course of the resultant electrical potential. At early developmental stages there are few AChRs on the surface. Because of their long open times, the channels would be very sensitive transducers, passing many ions per opening. Propagating action potentials do not occur in myocytes at this stage. Therefore, the $\mathrm{Na}^{+}$and $\mathrm{Ca}^{2+}$ entry would be localized to the region of muscle surface where a nerve fiber is approaching, with its growth cone secreting ACh (Hume et al., 1983; Young and Poo, 1983). The local buildup of ions could provide a spatial clue for the quick transformation of the region into a fully matured endplate. Although the data of Anderson et al. (1977) seemingly contradict this idea, their experiments did not address the present question directly.

\section{References}

Allen, C. N., and E. X. Albuqucrque (1986) Characteristics of acetylcholine-activated channels of innervated and chronically denervated skeletal muscles. Exp. Neurol. 91: 532-545.

Anderson, M. J., M. W. Cohen, and E. Zorychta (1977) Efrects of innervation on the distribution of acetylcholine receptors on cultured muscle cells. J. Physiol. (Lond.) 268: 731-756.

Auerbach, A., and C.J. Lingle (1986) Heterogeneous kinetic properties of acetylcholine receptor channel in Xenopus myocytes. J. Physiol. (Lond.) 378: 119-140.

Blackshaw, S., and A. Warner (1976) Onset of acetylcholine sensitivity and endplate activity in developing myotome muscles of Xenopus. Nature 262: 217-218.

Brehm, P., J. H. Steinbach, and Y. Kidokoro (1982) Channel open time of acetylcholine receptors on Xenopus muscle cells in dissociated ccll culturc. Dev. Biol. 91: 93-102.

Brehm, P., E. Yeh, J. Patrick, and Y. Kidokoro (1983) Metabolism of acetylcholine receptors on embryonic amphibian muscle. J. Neurosci. 3: 101-107.

Brehm, P., Y. Kidokoro, and F. Moody-Corbett (1984) Acetylcholine receptor channel properties during development of Xenopus muscle cells in culture. J. Physiol. (Lond.) 357: 203-217.

Brehm, P., L. Bates, R. Kream, and F. Mordy-Corbett (1985) Inhibition of acetylcholine receptor incorporation blocks developmental changes in channel gating in Xenopus muscle. Soc. Neurosci. Abstr. 11: 849 .

Brenner, H. R., and B. Sakmann (1983) Neurotrophic control of channel properties at neuromuscular synapses of rat muscle. J. Physiol. (Lond.) 337: 159-171.

Bridgman, P. C., S. Nakajima, A. S. Greenberg, and Y. Nakajima (1984) Freeze-fracture and electrophysiological studies of newly developed acetylcholine in Xenopus embryonic muscle cells. J. Cell Biol. 98: 2160-2173.

Carlson, C. G., R. J. Leonard, and S. Nakajima (1985) The aneural development of the acetylcholine receptor in the presence of agents which block protein synthesis and glycosylation. Soc. Neurosci. Abstr. 11: 156 .

Clark, R. B., and P. R. Adams (1981) ACh receptor channel populations in cultured Xenopus myocyte membranes are non-homogeneous. Soc. Neurosci. Abstr. 7: 838.

Colquhoun, D., and B. Sakmann (1985) Fast events in single-channel currents activated by acetylcholine and its analogues at the frog muscle end-plate. J. Physiol. (Lond.) 369: 501-557.

Eusebi, F., F. Grassi, C. Nervi, C. Caporale, S. Adamo, B. M. Zani, and M. Molinaro (1987) Acetylcholine may regulate its own nicotinic receptor-channel through the C-kinase system. Proc. R. Soc. London [Biol] 230: 355-365.

Fernández, J. M., F. Bezanilla, and R. E. Taylor (1982) Effect of chloroform on charge movement in the nerve membrane. Nature 297: $150-152$.

Fischbach, G. D., and S. M. Schuetze (1980) A post-natal decrease in acetylcholine channel open time at rat end-plates. J. Physiol. (Lond.) 303: 125-137.

Greenberg, A. S., S. Nakajima, and Y. Nakajima (1985) Functional properties of newly inserted acetylcholine receptors in embryonic Xenopus muscle cells. Dev. Brain Res. 19: 289-296.

Guharay, F., and F. Sachs (1984) Stretch-activated single ion channel currents in tissue-cultured embryonic chick skeletal muscle. J. Physiol. (Lond.) 325: 685-701.

Hamill, O. P., and B. Sakmann (1981) Multiple conductance states of single acetylcholine receptor channels in embryonic muscle cells. Nature 294: 462-464.

Hamill, O. P., A. Marty, E. Neher, B. Sakmann, and F. J. Sigworth (1981) Improved patch-clamp techniques for high-resolution current recording from cells and cell-free membrane patches. Pfluegers Arch. Physiol. 391: 85-100.

Hume, R. I., L. W. Role, and G. D. Fischbach (1983) Acetylcholine release from growth cones detected with patches of acetylcholine receptor-rich membranes. Nature 305: 632-634.

Igusa, Y., and Y. Kidokoro (1987) Two types of acetylcholine receptor channels in developing Xenopus muscle cells in culture: Further kinetics analyses. J. Physiol. (Lond.) 389: 271-300.

Jackson, M. W., B. S. Wong, C. E. Morris, and H. Lecar (1983) Successive openings of the same acetylcholine receptor channel are correlated in open time. Biophys. J. 42: 109-114.

Katz, B., and R. Miledi (1972) The statistical nature of the acetylcholine potential and its molecular components. J. Physiol. (Lond.) 224: 665-699.

Kidokoro, Y., and M. Saito (1987) Early cross-striation formation in twitching Xenopus myocytes. Soc. Neurosci. Abstr. 13: 467.

Kullberg, R., and J. L. Owens (1986) Comparative development of endplate currents in two muscles of Xenopus laevis. J. Physiol. (Lond.) 374: 413-427.

Kullberg, R. W., T. L. Lentz, and M. W. Cohen (1977) Development of the myotomal neuromuscular junction in Xenopus laevis: An electrophysiological and fine-structural study. Dev. Biol. 60: 101-129.

Kullberg, R. W., P. Brehm, and J. H. Steinbach (1981) Nonjunctional acetylcholine receptor channel open time decreases during development of Xenopus muscle. Nature 289: 411-413.

Lechleiter, J., and R. Gruener (1984) Halothane shortens acetylcholine receptor channel kinetics without affecting conductance. Proc. Natl. Acad. Sci. USA 81: 2929-2933.

Leonard, R. J., S. Nakajima, Y. Nakajima, and T. Takahashi (1984) Differential development of two classes of acetylcholine receptors in Xenopus muscle in culture. Science 226: 55-57

Magleby, K. L., and C. F. Stevens (1972) The effect of voltage on the time course of end-plate currents. J. Physiol. (Lond.) 223: 151-171.

Michler, A., and B. Sakmann (1980) Receptor stability and channel conversion in the subsynaptic membrane of the developing mammalian neuromuscular junction. Dev. Biol. 80: 1-17.

Mishina, M., T. Takai, K. Imoto, M. Noda, T. Takahashi, S. Numa, C. Methfessel, and B. Sakmann (1986) Molecular distinction between fetal and adult forms of muscle acetylcholine receptor. Nature 321: 406-411.

Neher, E., and B. Sakmann (1976) Noise analysis of drug induced voltage clamp currents in denervated frog muscle fibres. J. Physiol. (Lond.) 258: 705-729.

Nestler, E. J., S. I. Walaas, and P. Grecngard (1984) Neuronal phosphoproteins: Physiological and clinical implications. Science 225 . 1357-1364.

Nieuwkoop, P. D., and J. Faber (1967) Normal table of Xenopus laevis (Daudin), North-Holland, Amsterdam.

Owen, J. L., and R. Kullberg (1986) Development of acetylcholine receptor channel functions in vivo. Soc. Neurosci. Abstr. 12: 546.

Peper, K., R. J. Bradley, and F. Dreyer (1982) The acetylcholine receptor at the neuromuscular junction. Physiol. Rev. 62: 1271-1340.

Sachs, F., J. Neil, and N. Barkakati (1982) The automated analysis of data from single ionic channels. Pfluegers Arch. 395: 331-340.

Schuetze, S. M., and L. W. Role (1987) Developmental regulation of nicotinic acetylcholine receptors. Annu. Rev. Neurosci. 10: 403-457.

Siegelbaum, S. A., A. Trautmann, and J. Koenig (1984) Single acetylcholine-activated channcl currents in developing muscle cells. Dev. Biol. 104: 366-379.

Sine, S. M., and J. H. Steinbach (1984) Activation of a nicotinic acetylcholine receptor. Biophys. J. 45: 175-185.

Steele, J. A., and J. H. Steinbach (1986) Single channel studies reveal 
three classes of acetylcholine-activated channels in mouse skeletal muscle. Biophys. J. 49: 361a.

Steele, J. A., M. J. Poznansky, D. C. Eaton, and M. S. Brodwick (1981) Lipid vesicle-mediated alterations of membrane cholesterol levels: Effects on $\mathrm{Na}^{+}$and $\mathrm{K}^{+}$currents in squid axon. J. Membr. Biol. 63: 191-198.
Vicini, S., and S. M. Schuetze (1985) Gating properties of acetylcholine receptors at developing rat endplates. J. Neurosci. 5: 2212-2224.

Young, S. H., and M.-M. Poo (1983) Spontaneous release of transmitter from growth cones of embryonic neurones. Nature 305: 634-637. 